\title{
Analysis of Socio-Economic factors that Influence involvement in Resource Based Conflicts in Kenya
}

\author{
Eliud O. Ongowo ${ }^{1}$, Mwangi S. Wokabi ${ }^{2}$, and Ngetich Kibet ${ }^{3}$ \\ ${ }^{I}$ Department of Peace, Security and Social Studies Egerton University P.O. BOX 536 Njoro Kenya \\ ${ }^{2}$ Department of Peace, Security and Social Studies Egerton University P.O. BOX 536 Njoro Kenya \\ ${ }^{3}$ Department of Peace, Security and Social Studies Egerton University P.O. BOX 536 Njoro Kenya
}

\begin{abstract}
To effectively analyze the relationship between socio-economic factors and resource-based conflicts, the two variables were assessed in a number of dimensions. The five dimensions used to assess socio-economic factors include: education, ethnicity, employment status, religion and age. Resource-based conflicts, on the other hand, was assessed by considering two dimensions: involvement in resource-based conflicts and knowledge of the time of the conflicts. The dimensions were used so as to understand the two concepts under the study - socio-economic factors and resource-based conflicts. This study therefore examined the relationship between each of the dimensions of each variable and the dimensions of the other variable. The study used a structured questionnaire, in-depth interview schedule and an observation schedule to collect data. A standardized questionnaire was administered to selected household respondents. The data for the study was analyzed using Chi Square $\left(\chi^{2}\right)$, Cramer's V, Phi $(\phi)$ and Contingency co-efficient $(C)$ used to determine the relationship between socio-economic factors and involvement in resource-based conflicts and the strength of this relationship at $\alpha=0.05$ significance level. The study established that socio-economic factors influence the involvement in resource based conflicts.
\end{abstract}

Key Words: Socio-economic, Resource based conflicts, Relationship, Community

\section{Introduction}

Rift Valley Province now divided into 14 counties has remained the epicenter of resource-based conflicts [1]. The conflicts have mainly been over land and between the Agikuyu as "foreigners" and the Maasai, the Kalenjin and the Samburu as the "indigenous". The objective of the conflict has been to regain what "rightfully" belongs to the "indigenous" [2]. Conflicts over resources have also been experienced in other parts of Rift Valley including the Agikuyu versus the Kalenjin in Uasin Gishu district, Londiani and Molo - Elburgon, in the settlement schemes and Agikuyu versus the Maasai in Maela and Enoosupukia. There have also been brutal conflicts in Olenguruone and Bomet, between the Agikuyu and the Kalenjin. In addition, similar resource related conflicts were experienced in Laikipia pitting the Maasai against the large-scale ranchers. Lastly, resource-based conflicts have been experienced in Northern Kenya in which the perennial issues have been cattle rustling and grazing lands.

The study area, Longonot location experienced sporadic resource-based conflicts between the Maasai and the Agikuyu since 1995. In the year 2005, Longonot experienced a lot of resource-based conflicts. The conflicts were sparked by the need to access water points though it later turned out to be struggles for land resource. The Maasai view the Agikuyu as "foreigners" who have invaded their pre-colonial grazing lands [2]. The study area, Longonot location experienced sporadic resource-based conflicts between the Maasai and the Agikuyu since 1995. Rural households experienced conflicts with each other, relatives and neighbors and different ethnic groups are killing each other because of resources. The Maasai view the Agikuyu as "foreigners" who have invaded their pre-colonial grazing lands [2]. There have been contentions over land ownership and use, access to water resources and livestock theft. The study investigated the role of socio-economic factors in influencing involvement in resource-based conflicts.

\section{A Note On Methodology}

This study adopted a cross-sectional survey rather than a follow-up study due to time constraints. Information presented in this paper stems from various sources. Specific data inventories in this paper comprise of three categories. First, data collected through scheduled interviews, secondly data collected through dialogue with key informants and finally data collected through the researchers field observation and secondary information from existing data. 


\section{Results And Discussion}

The study determined the relationship between socio-economic factors and involvement in resource based conflicts. The relationship between socio-economic factors and resource-based conflict was determined using Crammer's V, Phi and Chi-square statistical tests. In order to effectively determine the relationship between socio-economic factors and resource-based conflict, the two variables were assessed in a number of dimensions [3]. The five dimensions used to assess socio-economic factors include: education, ethnicity, employment status, religion and age. Resource based conflict, on the other hand, was assessed by considering two dimensions: involvement in resource based conflict and knowledge of the time of the conflict. The dimensions were used so as to capture the full complexity of the two concepts under the study - socio-economic factors and resource based conflict. This study therefore examined the relationship between each of the dimensions of each variable and the dimensions of the other variable.

A. Education by involvement in Resources Based Conflicts

Table 1: Level of education by involvement in resource-based conflict

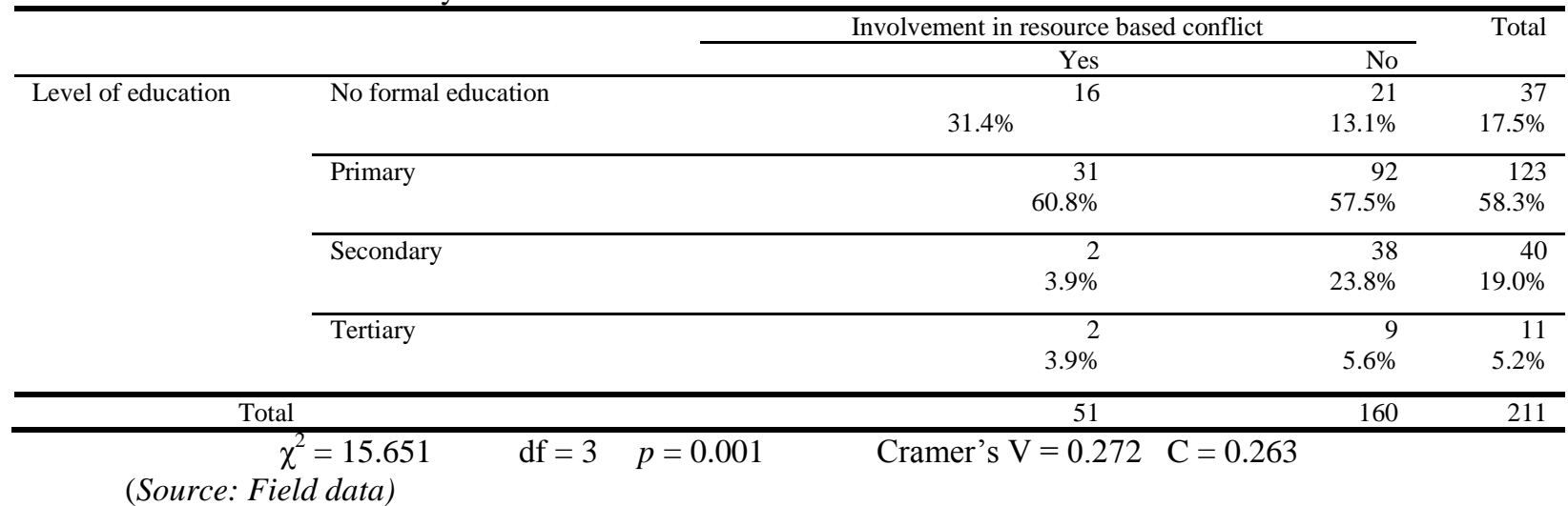

Table 1 suggests that there is a significant relationship between the level of education and involvement in resource based conflict. It can be observed that out of the 160 respondents who never got involved in the conflict, 86.9 percent had at least primary school level of education. Even for the 51 who were involved in the conflict, only 7.8 percent had secondary and tertiary level of education. This was further supported by the chisquare value $(p<0.05$ significant level), which suggests that there was a significant relationship between level of education and involvement in resource based conflict. In addition, Cramer's V and Contigency co-efficient values of 0.263 indicate a weak, positive and significant relationship between level of education and involvement in resource-based conflicts.

Table 1 suggests a weak, positive and significant relationship between the level of education and involvement in resource-based conflicts. It is clear that the more one advances in education, the less likelihood that the person will be involved in the resource-based conflicts. This relationship is be attributed to the fact that education increases the ability of one to understand issues more critically and objectively. In addition, education increases the intelligence of an individual and enables one to seek solutions rather than get involved in resource-based conflicts. This was evident from the table, which shows that as the level of education increased, the number of people who got involved in resource-based conflicts reduces.

The findings supports [4] who noted that education provides basic life skills and values that enable one to develop a sense of respect towards each other and shed prejudices of ethnicity. Similarly, the findings also agree with [5] findings that noted education enables people to think constructively about issues, both physically and socially, that need solutions to develop constructive attitudes of living in a community.

B. Ethnicity by Involvement in Resource-Based Conflicts

Table 2: Ethnic group by involvement in resource based conflict

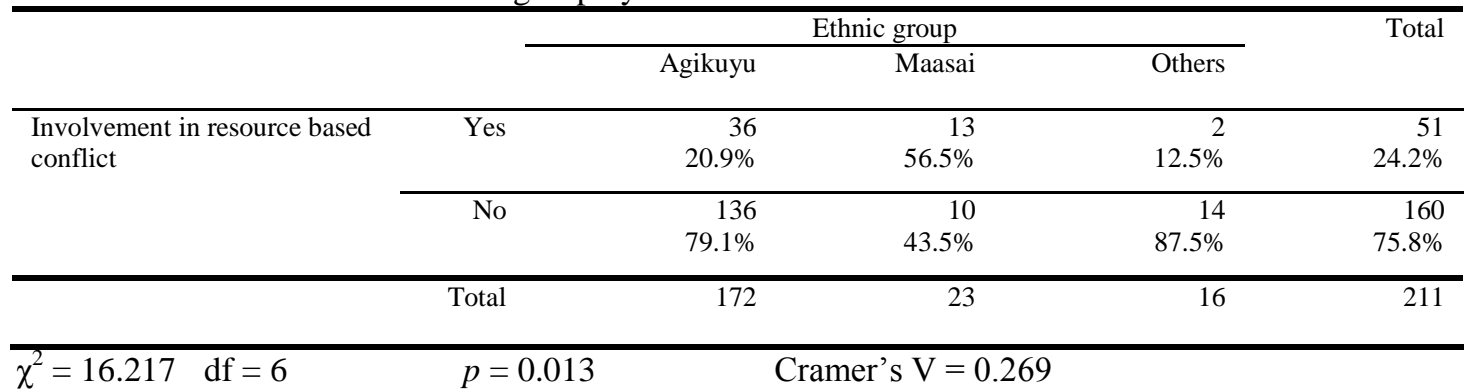




\section{(Source: Field data)}

An examination of Table 2 indicates that there is a significant relationship between ethnic group and involvement in resource-based conflicts. It can be observed that a bigger proportion of the respondents from the Maasai ethnic group were involved in the conflict than any other group. This is evident by the fact that 56.5 percent of the 23 Maasais interviewed were involved in resource based conflicts while only 20.9 percent of the 172 interviewed Agikuyus were involved in resource based conflicts. In addition, only 2 out of the 16 (Luo, Luhya, Akamba and Kisii) interviewed were involved in resource based conflicts. This further shows the existence of relationship between ethnicity and involvement in resource-based conflicts. These findings are supported by the chi-square value $(p<0.05)$ significance level. The results were further supported by Crammer's $\mathrm{V}$ value (0.269) suggesting a weak, positive and significant relationship between ethnicity and involvement in resource-based conflicts.

Table 2 show that there is a weak, positive and significant relationship between ethnicity and involvement in resource-based conflicts. The findings indicate that the Maasai community was more involved in the resource-based conflicts than their Agikuyu counterparts. This is attributed to the fact that while the Agikuyu dealt with issues on an individual basis, the Maasai dealt with issues, conflicts included, on a communal basis. For the Maasai, the involvement in the resource-based conflicts was a communal decision that was made by the elders on behalf of the entire community. On the other hand, the Agikuyu decided on issues on an individual basis on whether to get involved in the resource-based conflicts or not. This was supported by the reasons they gave for getting involved in the conflicts. For instance, avenge the killing of a family member; destruction of property while the Maasai involvement is triggered by the desire to protect "my" community.

Ethnic groups are seen to share a sense of distinctiveness that is marked by one or more cultural practices such as language, religion, kinship, organization, lifestyle or dress. Ethnicity is reinforced by institutional separation and a sense of distinct identity that emphasizes in-group commonalities and out-group differences. The result of dense within group social networks and weak ties to outsiders becomes important in mobilizing support once conflicts are defined in ethnic terms [6] [1] findings also agree with this as they noted that the Agikuyu are obvious targets for detestation by those whose property (land) they are accused of invading. [1] further notes that the conflicts that engulfed Rift Valley province was a function of several issues among them ethnocentrism.

Similarly, [7] views ethnicity as an enduring and prevailing attribute of social system consequently a natural fault line. Ethnic interests become ostensible rationale for conflict and are easy to justify ideologically and difficult for participants in conflict to resist. The language of ethnocentric mobilization is the language of kinship and it is imbued with highly sacred objects. To advocate for the use of strength in defense of such interests is heroic and noble. Those who oppose the defense of the group are easily characterized as either cowards or traitors [6].

To [8], ethnicity has often been used politically by invoking the differences that come with it. The politicians emphasize the ethnic differences for political mileage. In addition, [8] note that the state (Kenya during Moi's administration) continually called for the expulsion of non-Kalenjin, non-Maasai, non-Samburu and non-Turkana from the land in Rift Valley. [9] supports this by noting that bloody conflicts in rural KenyaRift Valley region raged before, during and after multiparty elections as the Kalenjin and their Maasai political allies attempted to drive their Agikuyu, Luo and Luhya political opponents out of the area.

\section{Occupation by Involvement in Resource-Based Conflicts}

Table 3: Occupation by involvement in resource-based conflict

\begin{tabular}{|c|c|c|c|c|}
\hline & & \multicolumn{2}{|c|}{ nvolvement in resource based conflict } & \multirow[t]{2}{*}{ Total } \\
\hline & & Yes & No & \\
\hline \multirow[t]{6}{*}{ Occupation } & Self-employment & 50 & 135 & 185 \\
\hline & & $98.0 \%$ & $84.4 \%$ & $87.7 \%$ \\
\hline & Formal Employment & 0 & 22 & 22 \\
\hline & & $0.0 \%$ & $13.8 \%$ & $10.4 \%$ \\
\hline & Unemployed & 1 & 3 & 4 \\
\hline & & $2.0 \%$ & $1.9 \%$ & $1.9 \%$ \\
\hline \multicolumn{2}{|l|}{ Total } & 51 & 160 & 211 \\
\hline
\end{tabular}

(Source: Field data)

Table 3 shows that there is a significant relationship between employment status and resource based conflicts. It can be observed that none of the 51 respondents who were involved in the conflict had formal employment. However, 13.8 percent of those who were not involved in resource-based conflicts had formal employment. The fact that majority of the people involved in the conflict were in self employment suggests that the conflict could 
have been associated with their occupational activities. This relationship was supported by the chi-square value ( $p<0.05$ significant level). Cramer's V value (0.193) and Contigency co-efficeint value (0.189) also indicate that there is a weak, positive and significant relationship between occupation and involvement in resource-based conflicts.

Table 3 indicates that there is a weak positive significant relationship between occupation and involvement in resource-based conflicts. It can be observed none of those in formal employment was involved in the resource-based conflicts. This relationship between employment status and involvement in resource-based conflicts could be attributed to the fact that formal employment is time consuming and ties one away from the community for longer periods of time. This limits one from involvement in the conflicts. Also formal employment increases the level of interaction and association of a person with the outside world and this might change his/her attitude toward causes of conflict back in the community. However, majority of the occupational activities involved in self-employment had direct linkages to the causes of conflicts in the area and thus increasing the chance of one being involved.

\section{Religion by Involvement in Resource-Based Conflicts}

Table 4: Religion by Involvement resource based conflict

\begin{tabular}{llrrr}
\hline & & \multicolumn{2}{c}{ Religion } & \multicolumn{2}{c}{ Total } \\
\cline { 3 - 5 } & & Christianity & None & \\
\hline $\begin{array}{l}\text { Involvement in resource based } \\
\text { conflict }\end{array}$ & Yes & 40 & 11 & 51 \\
& & $20.6 \%$ & $64.7 \%$ & $24.2 \%$ \\
\cline { 2 - 5 } & & & 154 & 160 \\
\hline Total & & $79.4 \%$ & $35.3 \%$ & $75.8 \%$ \\
\hline 576 & & 194 & 17 & 211 \\
\hline
\end{tabular}

(Source: Field data)

Table 4 indicates a significant relationship between religion and involvement in resource-based conflicts. It is clear that only 20.6 percent of the 194 respondents who professed Christianity were involved in the resourcebased conflicts. On the contrary, 64.7 of the 17 respondents who were not affiliated to any religion were involved in the resource-based conflicts. The chi-square value ( $p<0.05$ significant level) supports this relationship. The Phi value (-0.280) indicates an inverse relationship between religion and involvement in resource-based conflicts. This implies that the more people profess a religious affiliation, the lesser the likelihood of involvement in resource-based conflicts.

Table 4 indicates that there is an inverse significant relationship between religion and involvement in resource-based conflicts. As it can be observed from Table 4, the more one professes religious affiliation, the less likelihood of involvement in resource-based conflicts. This relationship can be attributed to the fact that Christian doctrines advocate for peace and love. In fact, Christianity decrees the faithful to love their neighbors as they love themselves. It is also expected that the church leaders preach peace among their flock.

\section{E Gender by Involvement in Resource-Based Conflicts}

Table 5: Gender by involvement in resource based conflict

\begin{tabular}{|c|c|c|c|c|}
\hline & & \multicolumn{2}{|c|}{ Gender } & \multirow[t]{2}{*}{ Total } \\
\hline & & Male & Female & \\
\hline \multirow{4}{*}{$\begin{array}{l}\text { Involvement in resource based } \\
\text { conflict }\end{array}$} & Yes & 47 & 4 & 51 \\
\hline & & $32.9 \%$ & $5.9 \%$ & $24.2 \%$ \\
\hline & No & 96 & 64 & 160 \\
\hline & & $67.1 \%$ & $94.1 \%$ & $75.8 \%$ \\
\hline
\end{tabular}

$\chi^{2}=18.309 \quad \mathrm{df}=1 \quad \mathrm{p}=0.000 \quad \phi=0.295$

(Source: Field data)

Table 5 shows that there is a significant relationship between gender and involvement in resource-based conflicts. Although 75.8 percent (160) of the sample did not get involved in resource based conflicts, more men (32.9\% of the males) than women (5.9\% of females) were involved in the resource based conflicts. This relationship between gender and resource based conflicts is further supported by the chi-square value $(p<0.05$ significant level). The Phi value (0.295) also indicates a weak, positive and significant relationship between gender and involvement in resource-based conflicts.

Table 5 indicate a weak positive and significant relationship between gender and involvement in resource-based conflicts. The relationship could be attributed to the cultural pre-disposition of the two communities. In both the communities women are never part of the warriors. Similarly, the traditional gender 
stereotyping and division of labor in both the communities is such that women are regarded to be weak physically and are expected to undertake domestic and reproductive responsibilities in the community, and household in particular. Men, on the other hand, are regarded to be strong physically and are expected to protect and safeguard the community and household in addition to undertaking economic responsibilities. More men are therefore expected to be involved in the conflict to protect and safeguard the community and its economic assets. According to the interviews conducted, Maasai women do not get involved in resource-based conflicts since they may be killed and no one will give birth to more warriors.

[10] noted that within the traditional gender divisions of labour women have a higher capacity for production and reproduction compared to fighting power and are therefore protected from risky occupation. Similarly, in studying pastoral conflicts, [10] found out that, boys are directly involved in the conflicts at least in defensive role.

\section{Conclusion}

From the above discussion, the study concludes that there is a relationship between socio-economic factors and involvement in resource-based conflicts. It is clear that education, ethnicity, occupation, religion and gender play a significant role in the involvement in resource-based conflicts. The findings and the discussion shows that the more one is educated, is in formal employment, belongs to a Christian institution, the less the likelihood of getting involved in resource-based conflicts. In addition, the study concludes that the resource-based conflicts assume ethnic dimensions due to the fact that the distribution of resources is commonly done along ethnic considerations. Lastly, the study concludes that the cultures of the communities determine which gender gets involved in the resource-based conflicts.

\section{References}

[1]. Ayiemba, H.O. E, Ayayo-Ochola, A.B.C, Omwanda O.L, Oucho, J.O (eds) Population and Development in Kenya Nairobi, School of Journalism Press 2000

[2]. CCR, Dialogue series Ethnicity, Violence and Democracy, 2003.

[3]. Bryman A. and Cramer D. Quantitative Data Analysis with SPSS for Windows; A guide for Social Science. New York: Routledge, 2001

[4]. Sinclair M. (2005) Building Citizenship and Life Skills. In Forced Migration Review Refugee Studies Centre in Association with Norwegian Refugee Council 2005

[5]. Baxter P. and Ikobwa V. Peace Education: Why and How. In Forced Migration: Education in Emergencies Refugees Studies Centre in Association with Norwegian Refugee Council 2005.

[6]. Ross H. and Rothman J. The Conflict, Management Implications of Major Theories of Ethnic Conflicts. Sri Lanka International Centre for Ethnic Studies Kandi, 1996

[7]. Hoyweghen V.S. and Vlassenroot K. Ethnic Ideology and Conflict in Sub-Saharan Africa; The Culture Clash Revisited. In Gorus J. and Doom R. (eds) Politics of Identity and Economics of Conflicts in the Great Lakes Region Brussels, VUB Press 2000. pp 93-94

[8]. Mekenkamp M, Paul V.T. \& Hans V.D. Search for Peace in Africa Netherlands, publication of European Platform for Conflict Prevention and Transformation1999.

[9]. Nnoli O. (ed) Ethnic Conflicts in Africa; A Comparative Analysis. London, CODESRIA, 1998

[10]. Kratli and Swift Understanding and Managing Pastoral Conflicts in Kenya Institute of Development Studies-University of Sussex, UK report 1999 